WrIGHT, J. (1955). J. gen. Microbiol. 12, 157-161

\title{
Non-motile Escherichia coli 055, B5 Strains
}

\author{
BY JOYCE WRIGHT*
}

St Ann's General Hospital, London, N. 15

SUMMARY: A description is given of twelve non-motile Escherichia coli 055 , B5 strains isolated during an outbreak of diarrhoea. Possible uses of such strains in serological practice and in epidemiological investigations are indicated.

Knowledge of the Escherichia coli group has been considerably extended by the studies of Kauffmann (see review, 1947), Vahlne (1945) and Knipschildt (1945, 1946) upon their antigenic structure. They used the term ' $K$ antigens' to comprise the $\mathbf{A}$ (capsular) and $\mathrm{L}$ and $\mathrm{B}$ (thermolabile, surface) antigens; strains possessing $\mathrm{K}$ antigen were not agglutinated in the living state by homologous $O$ antiserum and were described as O-inagglutinable (Kauffmann, 1944). $B$ antigens differed from $L$ antigens in that their agglutinin-binding power was not destroyed by heating; treatment of an $\mathrm{OB}$ antiserum with an $\mathrm{O}$ suspension of the homologous strain resulted therefore in the absorption of both the $\mathbf{O}$ and $B$ agglutinins (Knipschildt, 1945). The $O$ (somatic) antigens were shown to be thermostable and to resist heating at $100^{\circ}$.

Giles, Sangster \& Smith (1949) reported the isolation from infants with diarrhoea of a specific serological type of Escherichia coli which they termed the $\beta$ variety. Subsequently, Kauffmann $\&$ Dupont (1950) found that such strains possessed the antigens $\mathbf{O} 55$ and $\mathrm{B} 5$; their $\mathbf{H}$ antigens have been reported as types 2 (Laurell, 1952), 4 (Grönroos, 1954), 6 (Kauffmann \& Dupont, 1950), 7 (Krepler \& Zischka, 1952), 11 and 21 (Le Minor, Le Minor, Nicolle \& Buttiaux, 1954).

The present paper gives an account of twelve non-motile strains of Escherichia coli O55, B5. They were isolated by Dr K. B. Rogers, in 1952, during an outbreak of infantile diarrhoea in a residential nursery in Birmingham. Nine of the strains were derived from young children, one from a nurse and two from dust. Three strains were selected for more detailed investigation and have been designated $\boldsymbol{E}$. coli 886 (from a child), 899 (from a nurse) and 916 (from dust).

\section{METHODS}

Serological and biochemical tests. $\mathrm{O}$ and $\mathrm{OB}$ antisera were prepared with a representative Escherichia coli O55, B 5, H6 strain, designated $\beta$ 80; an OB antiserum with one of the test strains, $E$. coli 886 ; and antisera, for $\mathbf{H}$ agglutinin testing, with $E$. coli strains devoid of O55, B5 antigens, namely, Bi 7455/ 41 (O43, K ?, H2), 5680 (O111, B4, H4), A $20 a(\mathrm{O} 2, \mathrm{~K} 1, \mathrm{H} 6)$, and U 5/41 $(\mathrm{O} 1, \mathrm{~K} 1, \mathrm{H} 7)$. In addition, two antisera were kindly provided by Dr J. Smith

* Member of the Medical Research Council's Scientific Staff. 
for use in testing for $\mathrm{H}$ reactions; they were prepared with $E$. coli $\mathrm{Su} \mathrm{4321/41}$ (O13, K11, H11) and U11a/44 (O8, K?, H21).

Particulars of the preparation of Escherichia coli antisera, of their examination for certain non-specific agglutinins, and of the serological and biochemical methods used in testing $E$. coli strains have already been reported (Wright \& Villanueva, 1953a,b).

Tests for motility. Each of the twelve strains under investigation was subcultured into two Craigie tubes (Craigie, 1931) containing semi-solid nutrient agar ( $0.3 \%$ agar content), one tube being incubated at $37^{\circ}$ and the other at room temperature. The progress of the growth was observed daily. Examination of the outer growth for motility was made on the day when it was first observed on the surface of the medium and was repeated on each of the two subsequent days. Each Craigie tube culture was transplanted serially through a second and then a third Craigie tube; these were incubated under the same conditions as the first and were examined for motility in the same way.

In addition, strains 886,899 and 916 were subcultured daily for 12 days in semi-solid nutrient agar stabs, one series with each strain being incubated atroom temperature and the other at $37^{\circ}$. Each culture was examined daily for motility.

Tests for motility were carried out by the microscopic examination of hanging-drop suspensions in normal saline.

Staining for flagella. Stained preparations of strains 886, 899 and 916 were examined for the possible presence of flagella. Two $18 \mathrm{hr}$. MacConkey agar stab cultures and two 6-8 hr. nutrient broth cultures of each strain were tested, one of each duplicate set having been incubated at room temperature and the other at $37^{\circ}$. O55, B5 strains having $\mathrm{H}$ antigens 2, 6 or 7 were cultured in parallel, and on each slide prepared for the staining of a test strain one or other of these motile cultures was included as a control.

Mordant was freshly prepared by mixing $20 \mathrm{ml} .10 \%(\mathrm{w} / \mathrm{v})$ aqueous tannic acid with $20 \mathrm{ml}$. saturated aqueous potassium alum and then adding $2 \mathrm{ml} .10 \%$ (w/v) ferric chloride; after standing for 30 min., it was filtered through a Whatman no. 1 filter-paper. A little growth from each solid medium culture was transferred to $4 \mathrm{ml}$. distilled water and the suspension allowed to stand for 5 min.; each broth culture was centrifuged and the deposit also treated in this way. A loopful of each suspension was spread on a microscope slide and left to dry in air. Mordant was applied to the slide preparation for 3-5 min., washed off with distilled water and the slide gently blotted to remove excess water. Steaming Fontana's silver nitrate solution was flooded on to the slide and left for 3-5 min. The stain was then washed off with distilled water, the slide gently blotted, dried in air, mounted in Canada balsam and examined immediately under the oil-immersion lens.

\section{RESULTS}

Serological tests

$O$-inagglutinability and $B$ antigen tests. $\beta 80 \mathrm{O}$ antiserum at dilutions higher than $1 / 80$ did not agglutinate living suspensions of the twelve strains under investigation; it agglutinated to a titre of $1 / 3200$ their steamed suspensions. 
The strains were thereby shown to be ' $O$-inagglutinable', indicating that each possessed a thermolabile surface antigen (see Kauffmann, 1944). That this antigen was of the $\mathrm{B}$ kind was demonstrated by the results of the following test. $\beta 80 \mathrm{OB}$ antiserum $1 / 25$ was absorbed with $\mathrm{O}$ suspension of each of the strains 886, 899 and 916, and the absorbed antiserum was tested with saline suspensions of $\beta 80$ and of the three strains used for the absorption. In each instance, the absorption of both the $\mathrm{O}$ and $\mathrm{B}$ agglutinins was complete.

Tube-agglutination tests. $886 \mathrm{OB}$ antiserum agglutinated $\mathrm{OB}$ suspensions of $\beta 80$ and of the twelve strains under test to a titre of $1 / 800$. It agglutinated $O$ suspensions of all these strains to a titre of $1 / 6400$. It gave no agglutinative reactions with strains having $\alpha$-antigen of Stamp \& Stone (1944), $\beta$-antigen of Mushin (1949), a non-specific $O$ antigen (strain 'Straughan') or Vi antigen.

$\beta 80 \mathrm{OB}$ antiserum agglutinated $\mathrm{OB}$ suspensions of $\beta 80$ and of the twelve strains to a titre of $1 / 400$.

$\beta 80 \mathrm{O}$ antiserum agglutinated $\mathrm{O}$ suspensions of $\beta 80$ and of the twelve strains to a titre of $1 / 3200$.

Slide-agglutination tests. Both 886 and $\beta 80$ OB antisera gave prompt and complete slide agglutination of saline suspensions of $\beta 80$ and of the twelve strains.

Agglutinin-absorption tests. $886 \mathrm{OB}$ antiserum $1 / 25$, using $\mathrm{OB}$ antigens, (a) after absorption with $\beta 80$, was tested with this strain and with each of the strains 886, 899 and 916 , and $(b)$ after absorption with each of these three strains, was tested with $\beta 80$ and with the strain used for the absorption. Absorptions were carried out in the same way with (a) 886 OB antiserum 1/50, using $O$ antigens, $(b) \beta 80$ OB antiserum $1 / 25$, using $O B$ antigens and $(c) \beta 80$ $O$ antiserum $1 / 50$, using $O$ antigens. In each instance, absorption of the $O$ or OB agglutinins, respectively, was complete.

Possible $H$ antigens in test strains. Investigations were made for the possible possession of $\mathrm{H}$ antigens by the strains 886, 899 and 916. Accordingly, 8 and $18 \mathrm{hr}$. nutrient broth cultures and formol-saline suspensions from the surface growth of $(a)$ Craigie tube cultures in semi-solid nutrient agar, and $(b)$ MacConkey agar stab cultures were prepared. Each type of culture was incubated in duplicate at room temperature and at $37^{\circ}$. Tube-agglutination tests were carried out with these suspensions, using antisera prepared with Escherichia coli strains possessing $\mathrm{H}$ antigens of type $2,4,6,7,11$ or 21 but devoid of 055 , $\mathrm{B} 5$ antigens. No $\mathrm{H}$ agglutination reactions were observed at antiserum dilutions 1/50-1/12800. Conversely, 886 OB antiserum was tested for the possible presence of $\mathrm{H}$ agglutinins of types $2,4,6,7,11$ or 21 . E. coli strains possessing $\mathrm{H}$ antigen of one or other of these types, but devoid of O55, B5 antigens, were cultured in MacConkey agar stabs at room temperature for $18 \mathrm{hr}$. and formol-saline suspensions prepared from them. H agglutination reactions were not observed at antiserum dilutions 1/50-1/12800. In every series of tests, appropriate control tests of the $H$ antisera and suspensions were included and they yielded results which demonstrated the activity of the reagents employed. 


\section{Tests for motility}

The period taken for the growth of the twelve strains to progress through the Craigie tubes to reach the outer surface of the medium varied from 2 to 15 days. Inspection showed a characteristically non-motile type of Escherichia coli growth which extended up the outer side of the inner tube and across the surface of the medium but did not diffuse through it. Motile organisms were not observed in the microscopic examinations of the cultures.

The growth of strains 886, 899 and 916 throughout twelve daily passages in semi-solid nutrient agar stab cultures remained of the non-diffusive type and motile organisms were not observed by microscopic examination.

\section{Flagella staining}

Flagella were not observed in the stained preparations of strains 886,899 and 916. The control preparations of motile $055, \mathrm{B5}$ strains possessing $\mathbf{H}$ antigens of types 2, 6 or 7 all showed well-marked flagella development.

\section{Biochemical reactions}

The twelve strains under test produced acid and gas within $24 \mathrm{hr}$. at $37^{\circ}$ in arabinose, glucose, lactose, maltose, mannitol, and xylose, and in MacConkey broth at $44^{\circ}$; produced acid or acid and gas between 24 and $48 \mathrm{hr}$. at $37^{\circ}$ in sucrose and between 48 and $72 \mathrm{hr}$. in rhamnose; failed to ferment dulcitol, salicin, inositol, or inulin or to liquefy gelatin. They were methyl red-positive and Voges-Proskauer-negative; they produced indole, reduced nitrates to nitrites, did not utilize citrate, and did not produce urease.

\section{DISCUSSION}

Motile strains of Escherichia coli O55, B 5 have been isolated from infants with diarrhoea by a number of workers during recent years (Giles et al. 1949; Kauffmann \& Dupont, 1950). In 1953, however, Le Minor described three non-motile $E$. coli 055, B 5 strains received by her from Copenhagen and particulars of twelve non-motile $\boldsymbol{E}$. coli $\mathbf{O 5 5}$, B5 strains isolated in England are reported here. The latter strains differed in their fermentative reactions from the non-motile strains of Le Minor (1953) and from motile $E$. coli $055, \mathrm{B5}$ strains possessing $H$ antigens of types 2, 4, 6, 7, 11 or 21 (Kauffmann \& Dupont, 1950; Wright \& Villanueva, 1953 $a$; Le Minor et al., 1954; Grönroos, 1954); they formed, nevertheless, a biochemically homogeneous group. The twelve non-motile strains had been isolated from different individuals, or from dust, during an outbreak of diarrhoea in a nursery, and the uniformity of their biochemical activities suggests that such reactions may be of use in defining stable subtypes applicable to epidemiological investigations.

Two further points of interest in connexion with non-motile strains of Escherichia coli O55, B5 are their possible use in the preparation of OB antisera free from $H$ agglutinin (Wright \& Villanueva, 1954) and in $H$ antigen transduction experiments such as those undertaken with salmonella strains by Stocker, Zinder \& Lederberg (1953). 
Finally the importance of method in the examination of Escherichia coli strains for their possible motility may be stressed. It is evident from the work of Stuart \& Carpenter (1949) that the majority of $\boldsymbol{E}$. coli strains are motile; careful investigation of strains under conditions optimal for the development of motility (Wright \& Villanueva, 1953 $b$ ) is therefore required before this characteristic can be excluded and a report of non-motility be made.

I am indebted to Mr L. G. C. Maslen and other members of the staff of St Ann's General Hospital, and to Mrs Regina Villanueva of the Medical Research Council's staff, for their valuable assistance.

\section{REFERENCES}

Craigie, J. (1931). Studies on the serological reactions of the flagella of B. typhosus. J. Immunol. 21, 417.

Giles, C., Sangster, G. \& SMith, J. (1949). Epidemic gastro-enteritis of infants in Aberdeen during 1947. Arch. Dis. Childh. 24, 45.

Grönroos, J. A. (1954). Investigations on certain Escherichia coli sero-types with special reference to infantile diarrhoea. Ann. Med. exp. Fenn. 32, Suppl. no. 4.

Kauffmann, F. (1944). Zur Serologie der Coli-Gruppe. Acta path. microbiol. scand. $21,20$.

KaUfFManN, F. (1947). The serology of the coli group. J. Immunol. 57, 71.

Kaufrmann, F. \& Dupont, A. (1950). Escherichia strains from infantile epidemic gastro-enteritis. Acta path. microbiol. scand. 27, 552.

KNIPSCHILDT, H. E. (1945). Undersagelser over Coligruppens Serologi med saerligt Henblik paa Kapselformerne. Copenhagen: Arnold Busck, Nyt Nordisk Forlag. (English summary.)

KNIPSCHILDT, H. E. (1946). Demonstration of a new thermolabile antigen in the colon group. Acta path. microbiol. scand. 23, 179.

Krepler, P. \& Zischka, W. (1952). Zur Frage der ätiologischen Bedeutung des Bacterium coli O111, B4 bei Säuglingsenteritiden. Öst. $Z$. Kinderheilk. 7, 89.

LaUReLl, G. (1952). Ny serotyp av B. coli vid epidemisk diarré hos spädbarn. Nord. med. 47, 204.

Mrnon, S. LE (1953). Étude bactériologique d'Escherichia coli isolés au cours de gastro-entérites infantiles. Thèse Pharmacie Paris.

Minor, S. Le, Minor, L. Le, Nicolle, P. \& Buttiaux, R. (1954). Études sur les Escherichia coli isolés au cours des gastro-entérites infantiles. 1. Propriétés biochimiques et antigéniques. Ann. Inst. Pasteur, 86, 204.

Mushiv, R. (1949). A new antigenic relationship among faecal bacilli due to a common $\beta$ antigen. J. Hyg., Camb. 47, 227.

Stamp, Lord \& Stone, D. M. (1944). An agglutinogen common to certain strains of lactose and non-lactose-fermenting coliform bacilli. J. Hyg., Camb. 43, 266.

Stocker, B. A. D., Zinder, N. D. \& Lederberg, J. (1953). Transduction of flagellar characters in Salmonella. J. gen. Microbiol. 9, 410.

Stuart, C. A. \& Carpenter, P. L. (1949). Flagellar antigens of Escherichia coli. J. Immunol. 61, 161.

VAHLNe, G. (1945). Serological typing of the colon bacteria. Acta path. microbiol. scand. Suppl. no. 62.

Wright, J. \& Villanueva, R. (1953a). Differentiation of sero-fermentative types in Bacterium coli $\mathrm{O}$ group 55. J. Hyg., Camb. 51, 39.

Wright, J. \& Villanueva, R. (1953b). Methods for preparing $H$ antigens of Bacterium coli strains. J. Path. Bact. 66, 489.

Wright, J. \& Villanueva, R. (1954). The presence of $\mathrm{H}$ antigen in Escherichia coli K suspensions. J. Immunol. 72, 389. 